\title{
Job Demand, Family Social Support and Depression among the Royal Malaysia Police Officers of the Criminal Investigation Department in Selangor
}

Mohammad Arif Johari, Sa'odah Ahmad, Zanariah Ismail

To Link this Article: http://dx.doi.org/10.6007/IJARBSS/v11-i11/11779

DOI:10.6007/IJARBSS/v11-i11/11779

Received: 21 September 2021, Revised: 24 October 2021, Accepted: 10 November 2021

Published Online: 27 November 2021

In-Text Citation: (Johari et al., 2021)

To Cite this Article: Johari, M. A., Ahmad, S., \& Ismail, Z. (2021). Job Demand, Family Social Support and Depression among the Royal Malaysia Police Officers of the Criminal Investigation Department in Selangor. International Journal of Academic Research in Business and Social Sciences, 11(11), 2617-2632.

Copyright: (c) 2021 The Author(s)

Published by Human Resource Management Academic Research Society (www.hrmars.com)

This article is published under the Creative Commons Attribution (CC BY 4.0) license. Anyone may reproduce, distribute, translate and create derivative works of this article (for both commercial and non0-commercial purposes), subject to full attribution to the original publication and authors. The full terms of this license may be seen at: http://creativecommons.org/licences/by/4.0/legalcode

Vol. 11, No. 11, 2021, Pg. $2617-2632$

Full Terms \& Conditions of access and use can be found at http://hrmars.com/index.php/pages/detail/publication-ethics 


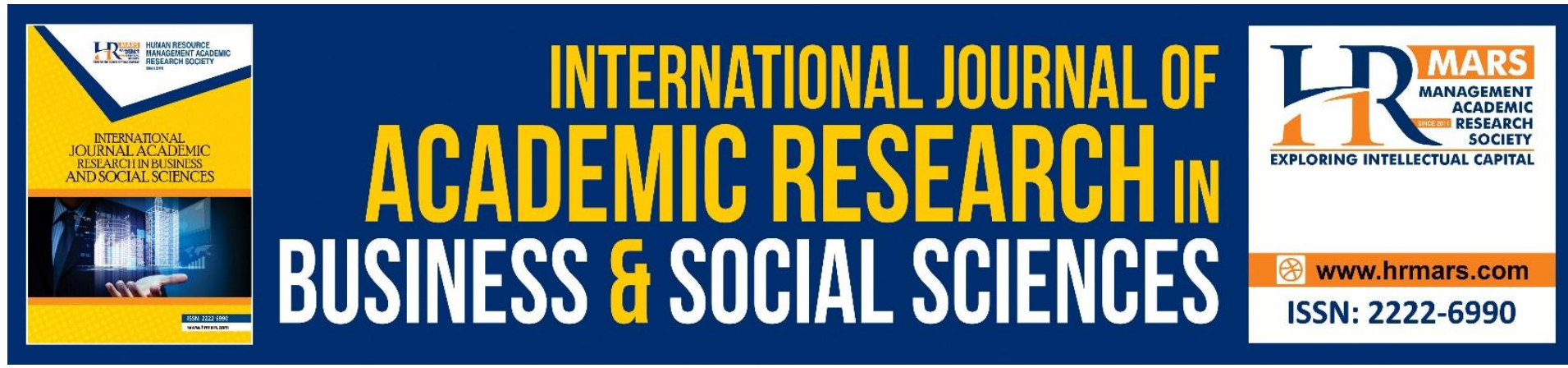

\title{
Job Demand, Family Social Support and Depression among the Royal Malaysia Police Officers of the Criminal Investigation Department in Selangor
}

\author{
Mohammad Arif Johari, Sa'odah Ahmad, Zanariah Ismail \\ Department of Human Development and Family Studies, Faculty of Human Ecology, \\ Universiti Putra Malaysia, 43400 Serdang, Selangor. \\ Email: saodahahmad@upm.edu.my
}

\begin{abstract}
This study was conducted to identify the relationship between job demands and family social support with depression among the Royal Malaysia Police (RMP) officers of the Criminal Investigation Department in Selangor. A total of 336 RMP officers of the Criminal Investigation Department were randomly selected as respondents of this study. Data were gathered through a self-administered questionnaire. The Depression Anxiety Stress Scale (DASS-21) (Lovibond \& Lovibond, 1995) was used to measure the level of depression among the respondents. Meanwhile, the Quantitative Workload Inventory (QWI) (Spector \& Jex, 1998) was used to measure the respondents' job demands and the Family Support Inventory for Workers (FSIW) (King et al., 1995) was used to measure the respondents' family social support. The results showed that there was a significant correlation between job demands, family emotional support and family instrumental support with depression among the respondents. The study also found that family instrumental support was the strongest predictor of the respondents' depression. Thus, the study concludes that any intervention program planned by the RMP to ensure the wellbeing of its officers particularly on the issue of depression must consider the aspect of job demands and family social support.
\end{abstract}

Keywords: Job Demands, Emotional Support, Instrumental Support, Depression, Police Officer.

\section{Introduction}

In Malaysia, RMP is the federal police force with the role of enforcing the safety of the country (Subri et al., 2011). The main task of a police officer is to protect the lives and property of the public as well as to fight and prevent crime in society. The RMP is the agency responsible for maintaining peace and public order that is not limited only to human-related peace but also includes any complication resulted from a natural disaster. The RMP is the first agency that will respond to the event of a threat from within and outside the country (Salmah, 2009). As such, police officers shoulder various forms of roles and pressures from the police organization in carrying out their integral and important responsibilities in maintaining 
national security. Symptoms of depression have been observed at a higher rate among police officers compared to the general public (Wang et al., 2010)

Depression refers to mental disorders that indicate feelings of depression, loss of interest and pleasure, decreased energy and self-esteem, guilt, sleep problems or poor appetite (World Health Organization, 2012). When this mental illness becomes chronic, it negatively affects the way an individual thinks and behaves. In the context of police officers, it can incapacitate the ability and resiliency of police officers in carrying out their duties. The main factors contributing to depression are work-family conflict and job demands (Griffin et al., 2018, Collins and Gibbs, 2003). The scope of work of police officers such as work environment, agency culture, inconsistent shift scheduling, long working hours, time stress, limited resources, threat and aggressive behavior from the public and presumably higher exposure to traumatic events contribute to chronic depression (Velden et al., 2013, Collins and Gibbs, 2003). Baka (2015) found that interpersonal conflict in the workplace, organizational constraints and workload quantity are factors that lead to increased depression and the effects of mental illness. As a result, police officers are more likely than the general population to suffer from depression, experience familial strife, misuse alcohol, and attempt suicide (Wang et al., 2010).

Family social support plays a vital role in reducing the risk of mental illness among police officers. According to Loriol (2016), police officers can be particularly vulnerable to poor mental health if they do not have support systems (family, friends, peers, trust from colleagues and supervisors), or if they lack personal qualities that empower them to cope. Previous studies have confirmed the importance of family support to function effectively in lowering the levels of work stress and depression and even acting as a positive effect in increasing self-esteem (Cohen et al., 2015). Low family support was found as a predictor of depressive symptoms among police officers (Sheeber et al., 1997).

In sum, police officers often experienced occupational stress and are consequently exposed to the high risk of developing mental illness which can jeopardize their wellbeing and job performance. The scarcity of studies on the relationship between job demand, family support and depression among police officers in Malaysia led the researchers to conduct this study. This study is important because depression is a mental illness that can affect the well-being of police officers as well as their families. The findings have the potential to be utilized by relevant authorities in planning for intervention programs on reducing depression and enhancing the wellbeing of police officers. Bearing in mind the importance of family and work context to a police officer, this study focuses on determining the job demands and family social support impact on the police officer's depression.

\section{Literature Review Depression}

Past studies have shown that policing is a stressful career and harms the mental and physical health of police officers, affecting their work performance and interactions with the public and can lead to moral conflict (Queiros et al., 2020; Ermasova et al., 2020; Papazouglu et al. 2020; Baldwin et al., 2019; Wassermann et al., 2019). Police are listed as one of the top three careers in Occupational Stress and Mental Illness Monitoring (SOSMI) globally (Ancient and Demou, 2019). The percentage of depression experienced by police officers globally ranging 
from 21.6\% among Taiwanese police (Chen et al., 2006) to $65.6 \%$ among Australian polices (Lawson et al., 2012). Differences in the percentage of depression may be due to the use of different study instruments and circumstances (Wickramasinghe et al., 2016).

Police officers are the first to be at the scene of a crime or dangerous situation and they are also the ones who provide the immediate assistance needed by the victim. This noble task is much needed by the community, but it can also put pressure on the physical and mental health of police officers. Police officers face critical security risks such as the possibility of serious injury or death, terrorist attacks, limited human and material resources, criticism from the public and society, lack of understanding from friends and family that can affect their psychological well-being and cause physical fatigue (Queiros et al., 2020; Purba \& Demou, 2019; Magnavita et al., 2018; Wang, 2010). The trauma faced by police officers is clearly stated by Violenti (in Hilliard, 2019):

"They see abused kids, they see dead bodies, they see horrible traffic accidents. And what that means is that the traumatic events and stressful events kind of build on one another... If you have to put a bulletproof vest on before you go to work, that's an indication you're already under the possibility of being shot or killed. So, all of these things weigh heavily on the psyche and over time, they hurt the officers" - John Violanti, 23-Year Police Veteran and Professor at University at Buffalo.

Studies on mental health in the workplace among police officers are focused mainly on the increasing levels of depression, anxiety, emotional and physical exhaustion, household problems, drug and alcohol abuse and increasing suicide cases among them (Queiros et. al., 2020; Husain \& Faize, 2018).

\section{Job Demands}

Job demands include long shifts, job role ambiguity, job role conflicts, shift work hours and physical and psychological efforts that contribute to work stress and affect work-family conflict and mental health (Mazlan et al., 2021; Burke et al., 1980; Grzywacz et al., 2007; Frone, 2000; Jones \& Butler, 1980; Katz \& Piotrkowski, 1983; Mazerolle, 2008; Staines \& Pleck, 1983; Thomas \& Ganster, 1995; Thompson \& Prottas, 2005; Voydanoff, 1988). Many factors lead to an increase in the job demands of police officers. However, this study specifically only examines job demands that focus on organizational stress and workload stress.

A study by Wolter et al (2019) found that organizational stress is a predictor factor for the emotional exhaustion of police officers. This situation is because organizational factors lead to an increase in work protocols while performing outside tasks. In the situation caused by the Covid-19 Pandemic today, the police officers who are the front liner of the country are the ones who directly interact with the public because they are members of the law enforcement agency. As the law enforcers, police officers bear additional job demands from the organization due to the existence of policies or new policies such as Movement Control Orders during the Pandemic of Covid-19. Exposure to additional job demands, environment and strict security protocols daily as well as non-compliance by community members with these new policies and restrictions can put pressure and anxiety on police officers that lead to depression (Stogner et al., 2020; Shirzad et al., 2020). 
The workload of police officers depends on the position, type and place they are assigned. Police officers who carry out administrative work are usually more comfortable when dealing with others than those who work in the field doing an investigation on the crime scene. This situation is due to the uncertainty factors that may occur in the career field and the form of interaction encountered while performing the task.

\section{Job Demands and Depression}

This study focuses on the relationship of job demands with depression among police officers. A review of previous studies shows that policing is a job that puts stress and impacts the level of physical and mental health (Queiros, 2020). Studies on the level of depression due to job demands are increasing in line with the awareness of the need to improve the quality of work and well-being of police officers (Eurofound, 2018). According to Spector and Jex (1998), the three factors of job demand, namely interpersonal conflict in the workplace, organizational constraints and workload demands (workload demand) are the main factors of psychological stress.

The increasing demand for police works each year increases the pressure on police personnel (Baka, 2015; Webster, 2013). A career as a police officer is considered to be at high risk for mental problems (Velden et al., 2013) and emotional exhaustion (Jacobsson et al., 2017). Gray and Rydon-Grange (2020) found that the demands of police officers who often face traumatic events while helping victims indirectly caused them to be at risk of stress and post-traumatic stress disorder. They further asserted that investigating police personnel involved with the work environment and traumatic victims may experience traumatic imagery, moderate traumatic stress, traumatic response transfer, fatigue and impulsive feelings of compassion to the symptoms of depression. These findings are in agreement with a study conducted by Collazo (2020), which concluded that police officers who have experienced high stress are those who are often faced with traumatic task situations. Traumatic means a very shocking event that leaves a deep and lasting impression (Dewan Bahasa dan Pustaka, 2005). This feeling of trauma is long-lasting and still felt even after completing his duties as a police officer.

\section{Family Social Support}

Social support is identified as a vital component in forming strong relationships and psychological wellbeing. Social support is defined as a combination of social relationships, emotional and behavioral interactions, and individual perceptions of the availability attitudes of various types of support (Button, 2008). This social support includes the amount of support a person receives and phenomena involving interactions between two individuals who have a role to play in health (Argustaite-Zailskienè et al., 2020). Social support involves a network of family and friends that can be referred to when an individual is in trouble. The support or assistance provided by family members and friends increases physical and psychological comfort for individuals facing stressful situations (Chesla et al., 2010). Individuals become part of the family through various means: marriage, birth, adoptive family.

Family social support is defined as the process of providing information that brings confidence to individuals that their basic social needs are met through interaction with family members. Family support can be categorized into structural and functional aspects. The structural aspect is related to the integration of the individual with the family social support network 
while the functional aspect refers to the function or role given or acquired. The functional support aspect refers to the nature of family support which is classified into four main domains namely instrumental support, emotional support, information support and social integration. Instrumental support refers to the help given by family members in tidying up the house, providing transportation or money while emotional support refers to a person's feelings about being liked, admired, respected, or loved while information support involves providing information when an individual is under stress (King et al., 1995). Social integration refers to the involvement of individuals in groups that have common interests and activities (Elkhaldi, 2013).

\section{Family Social Support and Depression}

In general, social support received from family members, friends and the environment has a significant relationship with the physical and psychological health of individuals (Gouveia et al., 2016; Wang et al., 2010). LaRocco, House and French (1980) found that a significant relationship between family social support and personal well-being can lower levels of individual depression and anxiety. The study of Estrada Pineda et al. (2012) showed that after 16 weeks of depressed police officers undergoing family social support therapy, there was improvement and improvement in dealing with depression. This study found that an increase in family social support successfully reduced the level of depression of police officers.

Family social support is a significant indicator of mental health (depression) in which individuals who do not have good family relationships and have low levels of support from families show higher depression scores (Jones \& Logan, 2013). Family relationships and social support are also more significant compared to friendships (Stice et al., 2004) are important factors to help reduce the stress experienced by police officers as a result of work-family conflicts and work demands. Family and relative support act as buffers (buffer) of work stress (Tonsing, Zimet \& Tse, 2012; Cortes, 1985). A previous study has shown that social support was found significant with occupational stress (Halif et al., 2020)

Support from couples is associated with low levels of depression and family support is a protective factor from depression in adults (Gariepy, Honkaniemi \& Quesnel-Vallee, 2016) This finding is also supported by a study by Elkhaldi (2013) conducted on patients with depression in Gaza. Findings prove that family social support has an impact on the patient's recovery process

\section{Research Methodology \\ Research Design}

This study used quantitative methods and the research design was correlation and descriptive research. The correlation design was chosen because the study focused on the relationship between job demands and family supports with depression among police officers working in the Criminal Investigation Department in the Selangor District Headquarters (IPD). Selangor was selected as the location of the study based on the statistic from the Department of Integrity and Standard Compliance, RMP (2020) that police officers in Selangor are the highest in experiencing issues on career, personal, psychology and family. The police officers working in the Criminal Investigation Department were chosen as the respondents of the study because their scope and nature of work met the objectives of the research. A selfadministered questionnaire was used to gather the data of the respondents' characteristics 
(age, gender, marital status, number of children and number of years of education) and scores for each scale used in this study. The respondents were selected using a random sampling technique. The total number of respondents in this study was 336. A consent form for the respondents to participate voluntarily was obtained before the distribution of the questionnaires. The confidentiality of the information provided was also emphasized to the respondents. The study had also obtained approval from the Ethics Committee for Research Involving Human Subject Universiti Putra Malaysia (JKEUPM-2019-268).

\section{Instrumentation}

A set of bilingual Bahasa Melayu-English questionnaires was used to measure job demands, family social support and depression. The distribution of the questionnaires was made possible with the help of the connecting officers in the IPD.

Depression was measured using the Depression Anxiety Stress Scale (DASS-21) by Lovibond and Lovibond (1995) which was translated into Bahasa Melayu by Ramli Musa from the International Islamic Universiti Malaysia. The scale contains 21 items that measure depression, anxiety, and individual stress. Measurements are in the form of a four-point Likert scale namely ' $0=$ Not Applied to me,' $1=$ Applied to me for some stage or some time ',' $2=$ Applied to me for some time ', and ' 3 = Applied to me most of the time '. The Cronbach's alpha value recorded was 0.80 for the entire scale. The Cronbach's alpha value for depression in this study is 0.80 .

Job demand was measured using the Quantitative Workload Inventory (QWI) scale developed by Spector and Jex (1998). This scale contains 5 items. QWI is a 5-item scale designed to assess the quantity of work in a job as a qualitative workload that is the difficulty of working in an organization. In this scale, there are 5 Likert scales used, namely ' $1=$ Less than Once a Month, '2 = Once or Twice a Month, ' ' 3 = Once or Twice a Week ', ' 4 = Once or Twice a Day, ' 5 = Several Times a Day '. The high score obtained represents a high level of job load (score range - 5 to 25). Sample items from the QWI scale are: how often does your employer require you to work quickly? How often are there many things to do? A study by Spector and Jex (1998) reported that the average consistency in Cronbach's alpha of this scale was 0.82 . The alpha Cronbach value obtained by this study is 0.935 .

Family social support was measured using the Family Support Inventory for Workers (FSIW) developed by King et al (1995). This scale contains 44 items containing 2 subscales namely emotional support (29 items) and instrumental support (15 items). Items in this scale have 5 Likert points namely ' $1=$ Strongly Disagree', '2 = Disagree', ' $3=$ Sometimes Disagree', ' 4 = Agree', ' 5 = Strongly Agree'. The reliability value of Cronbach's alpha in the previous study for the emotional support subscale was between 0.95 to 0.97 while the instrumental support was 0.93 to 0.94 .

\section{Statistical Analysis}

The data obtained were analyzed using the Statistical Package for Social Science (SPSS) Version 19.0. Descriptive statistics were used to describe the respondent's characteristics, job demands, family social support (emotional and instrumental) and depression level. The Pearson's Correlation Coefficient Test was used to determine the relationship between job 
demands and family social support with the respondents' depression. Lastly, multiple regression was used to determine the unique predictor for the respondents' depression.

\section{Results of Analysis}

\section{Personal Characteristics of the Respondents}

Table 1 shows descriptive data on the personal characteristics of the respondents namely gender, age, marital status, number of children and number of years of education. Based on the analysis, the total number of respondents were 336 people consisting of male respondents of 66.7 percent $(n=227)$ and female respondents of 32.4 percent $(n=109)$. Besides, the percentage of respondents aged 19 to 38 years was 60.4 percent $(n=203)$. The percentage of respondents aged between 39 to 58 years was 38.1 percent $(n=128)$ while the percentage of respondents aged over 58 years was 1.2 percent $(n=5)$.

The majority of respondents have a married marital status (97.6 percent, $n=328$ ) followed by divorced respondents of 2.4 percent $(n=8)$. Most respondents had 1 to 5 children $(84.2$ percent, $n=283$ ). Meanwhile, respondents with no children were 10.4 percent $(n=35)$, respondents with 6 to 10 children were 5.1 percent $(n=17)$ and respondents with more than 10 children were 0.3 percent $(n=1)$.

In terms of the number of years of education, as many as 0.3 percent $(n=1)$ respondents had a total number of years of education between 1 to 6 years (UPSR). The percentage of respondents who had a total year of education of 7 to 9 years (PMR / PT3) was 2.1 percent (n $=7$ ). Almost half of the respondents (49.7 percent, $n=167$ ) had a total year of education between 10 to 11 years (SPM) and followed by 27.4 percent $(n=92)$ respondents had a total year of education between 12 to 14 years (STPM / Foundation / Matriculation). A total of 17.3 percent $(n=58)$ of respondents had a total year of education between 15 to 18 years (Bachelor) while the percentage of respondents who had a total year of education between 19 to 21 years (Master) was 2.4 percent $(n=8)$. The percentage of respondents who had a total year of education between 22 to 24 years $(P h D)$ was 0.3 percent $(n=1)$ and the percentage of respondents who had a total year of education of 25 years and above was 0.6 percent $(n=2)$. 
Table 1: Personal Characteristics of Police Officers $(n=336)$

\begin{tabular}{lll}
\hline Demography & Frequency $\mathbf{( n )}$ & Percentage (\%) \\
\hline Gender & 227 & 67.6 \\
Male & 109 & 32.4 \\
Female & & \\
\hline Age & 203 & 60.4 \\
19-38 years old & 128 & 38.1 \\
$39-58$ years old & 5 & 1.2 \\
>38 years old & & \\
\hline Marital Status & 328 & 97.6 \\
Married & 8 & 2.4 \\
Divorce & & \\
\hline Number of children & 35 & 10.4 \\
Do not have children & 283 & 84.2 \\
1-5 children & 17 & 5.1 \\
6-10 children & 1 & 0.3 \\
$>10$ children & & \\
\hline Number of years of education & 1 & 0.3 \\
1-6 years (UPSR) & 7 & 2.1 \\
$7-9$ years (PMR/PT3) & 167 & 49.7 \\
$10-11$ years (SPM) & 92 & 27.4 \\
12-14 years & & \\
(Diploma/Foundation/Matriculation) & 58 & 17.3 \\
15-18 years (Bachelor) & 8 & 2.4 \\
19-21 years (Master) & 1 & 0.3 \\
22-24 years (PhD) & 2 & 0.6 \\
25 years and above & & \\
\hline
\end{tabular}

Levels of Job Demands, Family Social Support and Depression of the Respondents

Table 2 shows the job demands of respondents in three levels namely low, medium, and high levels. The results of the study reported that most respondents ( 61.9 percent, $n=208$ ) had a moderate level of job demands. This was followed by 24.7 percent $(n=83)$ respondents who reported having a high level of job demands. Only 13.4 percent $(n=45)$ of respondents reported having a low level of job demands. Overall, the findings of this study revealed that most of the respondents experienced a moderate level of job demands.

Table 2: Job Demands ( $n=336)$

\begin{tabular}{lcc}
\hline \multicolumn{1}{c}{ Job Demands } & Frequency & Percentage (\%) \\
\hline Low & 45 & 13.4 \\
Moderate & 208 & 61.9 \\
High & 83 & 24.7 \\
\hline Total & 336 & 100.0 \\
\hline
\end{tabular}

Table 3 shows that 72.3 percent $(n=243)$ of the respondents reported having a moderate level of emotional support and 14.9 percent $(n=50)$ of the respondents reported having high emotional support. Only 12.8 percent $(n=43)$ of respondents reported having a low level of 
emotional support. Overall, the data showed that most of the respondents in this study received moderate emotional support from family members.

Table 3: Emotional Support $(n=405)$

\begin{tabular}{lcc}
\hline \multicolumn{1}{c}{ Emotional Support } & Frequency & Percentage (\%) \\
\hline Low & 43 & 12.8 \\
Moderate & 243 & 72.3 \\
High & 50 & 14.9 \\
\hline Total & 336 & 100.0 \\
\hline
\end{tabular}

Table 4 shows most respondents (70.8 percent, $n=238$ ) had a moderate level of instrumental support. This was followed by 16.4 percent $(n=55)$ respondents who reported having a high level of instrumental support. Only 12.8 percent $(n=43)$ of respondents reported having a low level of instrumental support. Overall, the findings showed that most of the respondents in this study received instrumental support from the family.

Table 4: Instrumental Support $(n=336)$

\begin{tabular}{lcc}
\hline \multicolumn{1}{c}{ Instrumental Support } & Frequency & Percentage (\%) \\
\hline Low & 43 & 12.8 \\
Moderate & 238 & 70.8 \\
High & 55 & 16.4 \\
\hline Total & 336 & 100.0 \\
\hline
\end{tabular}

Table 5 shows the level of respondents' depression which was divided into 5 levels namely normal, mild, moderate, severe, and extremely severe. This calculation was based on psychometrics by Lovibond and Lovibond (1995). The sum of each item showing a score between 0 to 9 was interpreted as normal, a score between 10 to 13 was interpreted as mild, a score between 14 to 20 was interpreted as moderate, a score between 21 to 27 was interpreted as severe and a score of 28 and above was interpreted as very severe. The results of the study found that most of the respondents, which is 73.2 percent $(n=246)$ reported a normal level. Meanwhile, 15.2 percent $(n=51)$ of respondents had moderate depression. This was followed by 13.3 percent $(n=43)$ of the respondents with mild depression and 0.3 percent $(n=1)$ of the respondents with severe depression. No respondent reported having an extremely severe level of depression. The data showed that depression is experienced by the RMP officers. Even though the percentage of the respondent with severe depression is only 0.3 , the RMP should take this as an indication that an intervention program is needed to be planned and implemented as a preventive measure.

Table 5: Depression $(\mathrm{n}=336)$

\begin{tabular}{lcc}
\hline \multicolumn{1}{c}{ Depression } & Frequency & Percentage (\%) \\
\hline Normal (0-9) & 246 & 73.2 \\
Mild (10-13) & 38 & 11.3 \\
Moderate (14-20) & 51 & 15.2 \\
Severe (21-17) & 1 & 0.3 \\
Extremely severe (>28) & 0 & 0.0 \\
\hline Total & 336 & 100.0 \\
\hline
\end{tabular}




\section{The Relationship Between Job Demand and Family Social Support (Emotional Support and Instrumental Support) with the Respondents' Depression.}

To determine the relationship between job demands and respondents' depression, a Pearson's Correlation Coefficient Test was conducted. The results of this study showed that there was a significant relationship between job demands and depression because the value of $r=0.143^{* *}$ and the value of $p=0.009$ (refer to table 6). This means that job demands affect depression. This finding is in line with the study by Baka (2015) who found that there is a significant relationship between job demands and depression among police officers. Job demand factors (Brown \& Campbell, 1990; Kop et al., 1999), police career pressures such as organizational stress, the scope of police work, supervisor management style, poor team communication, equipment that does not meet work requirements, increased demand for paperwork by supervisors, poor training, tiring shifts, and inadequate salaries affect the mental health of police officers namely depression (Brown et al., 1999). The higher the job demands, the higher the depression experienced by the police officers.

Table 6: Correlation between Job Demands and Depression ( $\mathrm{n}: 336)$

\begin{tabular}{lcc}
\hline Variables & \multicolumn{2}{c}{ Depression } \\
\cline { 2 - 3 } & $\mathrm{r}$ & $\mathrm{p}$ \\
Job Demands & $0.143^{* *}$ & 0.009 \\
\hline
\end{tabular}

Note: $p \leq 0.05, * * p \leq 0.01, * * * p \leq 0.001$

The relationship between emotional support and respondents' depression was measured using Pearson's Correlation Coefficient Test. The result showed that there was a significant relationship between emotional support and depression because the value of $r=0.296^{* *}$ and the value of $p<0.000$ (refer to Table 7). This means that emotional support affects depression. The negative relationship between emotional support and depression indicated that an increase in emotional support will decrease depression.

This finding is consistent with Lincoln and Chae (2011) which also found that there was a negative and significant association between emotional support and depression. Emotional support is a protective factor received from family members to lower the level of depression. Emotional support can be seen when the family members (spouse or children) frequently support the working family members, feel loved and cared for, hearing the problems at work, and are concerned about the well-being of working family members (Lincoln \& Chae, 2011).

Table 7: Correlation between Emotional Support and Depression (n: 336)

\begin{tabular}{lcc}
\hline Variables & \multicolumn{2}{c}{ Depression } \\
\cline { 2 - 3 } & $r$ & $p$ \\
Emotional support & $0.296^{* *}$ & 0.000 \\
\hline
\end{tabular}

Note: $p \leq 0.05,{ }^{* *} p \leq 0.01,{ }^{* * *} p \leq 0.001$

The Pearson's Correlation Coefficient Test was used to determine the relationship between instrumental support and the respondents' depression. The test result showed that there was a significant and negative relationship between respondents' instrumental support and depression because of the value of $r=0.343^{* *}$ and the value of $p<0.000$ (Table 8). This means that instrumental support affects the level of depression of the respondents. The result of this study was consistent with the study by Allison et al., (2019) which found that instrumental 
support is a type of social support that works and affects the decline of depression's level. This suggests that social support is a buffer factor that impacts depression among individuals (Fauth et al., 2012).

Table 8: Correlation between Instrumental Support and Depression (n: 336)

\begin{tabular}{lcc}
\hline Variables & \multicolumn{2}{c}{ Depression } \\
\cline { 2 - 3 } & $\mathrm{r}$ & $\mathrm{p}$ \\
Instrumental support & $0.343^{* *}$ & 0.000 \\
\hline
\end{tabular}

Note: $p \leq 0.05,{ }^{* *} p \leq 0.01,{ }^{* * *} p \leq 0.00$

Multivariate Analysis to Determine the Unique Predictor of the Respondents' Depression. Based on the result shown in Table 9, instrumental support, job demands and emotional support were found to be significant factors to predict depression. $(F=8.601, p<0.01)$. The instrumental support seems to be the strongest predictor of the respondents' depression. Data showed that 7 percent of the variance $\left(R^{2}=0.072\right)$ of depression was explained by the model. The finding of this study concurred with past studies which upheld that instrumental support (family members help to manage household chores, prepare food, and buy daily items for the family) managed to reduce the burden on respondents (Parasuraman, 1996)

Table 9: Multiple Regression of Depression (n:336)

\begin{tabular}{lccc}
\hline Variables & \multicolumn{3}{c}{ Depression } \\
\hline & B & SE.B & Beta, $\boldsymbol{\beta}$ \\
\hline Job Demands & 0.472 & 0.283 & 0.091 \\
Emotional Support & 0.306 & 0.468 & 0.047 \\
Instrumental Support & 1.226 & 0.455 & 0.197 \\
$R^{2}$ & & 0.072 & \\
Adjusted $R^{2}$ & & 0.064 & \\
F & & 8.601 & \\
\hline
\end{tabular}

\section{Study Implication}

This study proves that police officers experienced depression in carrying out their duties. Family social support, as well as job demands, were found to influence depression. Awareness and knowledge of high-risk factors in influencing depression which stems from aspects of job demands and the role of family support as a protective factor allow more effective measures to be taken to address them. Apart from that, this study also has implications for the RMP organization where the data of this study can be used as the basis for prevention, advocacy, and intervention programs to address the issue of depression among police officers. For example, the Religious and Counseling Division (BAKA) of the RMP can organize awareness programs on depression, self-motivation, family strengthening and prevention programs to enhance the ability of the police officers to cope with the job demands and conflicts arising in their daily lives and duties as well as family bonding.

\section{Conclusion}

A career as a police officer exposes a person to a high risk of mental problems (Van Der Velden et al., 2013) and emotional exhaustion (Jacobsson et al., 2017). Depression is a mental illness or disorder that causes a person among others to feel prolonged sadness, fatigue or lack of energy, irritability and loss of interest in daily activities. Mental health is a vital factor in 
determining an individual's willingness to take on challenges in the workplace and family life. Carrying out challenging and risky police duties as in the Criminal Investigation Department requires high focus and commitment. Wise management and family-oriented programs by the agency of the workplace need to be planned and executed together as solutions to overcome depression because this study has proven that family social supports and job demands are predictors of police officers' depression. In conclusion, mental health issues such as depression among police officers should be given serious attention. Appropriate action should be taken by the authorities to prevent a mental health illness among police officers. This is because the police officers must be rational and of sound mind in performing the heavy and important task of protecting public safety.

\section{Acknowledgements}

The authors thank the RMP and the police officers from the Criminal Investigation Department in the Selangor IPD for their involvement as respondents in this study.

\section{References}

Allison, P., Mnatsakanova, A., McCanlies, E., Fekedulegn, D., Hartley, T. A., Andrew, M. E., \& Violanti, J. M. (2019). Police stress and depressive symptoms: role of coping and hardiness. Policing, 43(2), 247-261. https://doi.org/10.1108/pijpsm-04-2019-0055

Argustaitè-Zailskienè, G., Šmigelskas, K., \& Žemaitienè, N. (2020). Traumatic experiences, mental health, social support, and demographics as correlates of alcohol dependence in a sample of Lithuanian police officers. Psychology, Health \& Medicine, 25(4), 396-401

Baka, L. (2015). The Effects of Job Demands on Mental and Physical Health in the Group of Police Officers. Testing the Mediating Role of Job Burnout. Studia Psychologica, 57(4), 285-299. doi:10.21909/sp.2015.03.700

Burke, R. J., Weir, T., \& DuWors, R. E. (1980). Work demands on administrators and spouse well-being. Human Relations 33(4), 253-278.doi:10.1177/001872678003300404

Chen, H. C., Chou, F. H., Chen M. C., Su, S. F, Wang, S. Y., Feng, W. W., Chen, P. C., Lai J. Y., Chao, S. S., Yang, S. L., Tsai, T. C., Tsai, K. Y., Lin, K. S., Lee, C. Y., Wu, H. C. (2006). A survey of quality of life and depression for police officers in Kaohsiung, Taiwan. Qual Life Res, 15, 925-932. doi: 10.1007/s11136-005-4829-9

Chesla, C. A. (2010) Do Family Interventions Improve Health? Journal of Family Nursing 16(4), 355-377.doi:10.1177/1074840710383145

Collazo, J. (2020). Adapting Trauma-Focused Cognitive Behavioral Therapy to Treat Complex Trauma in Police Officers. Clinical Social Work Journal, 1-10.

Department of Integrity and Standard Compliance, RMP (2020).

Elkhaldi, A. (2013). The Impact of Family Support on Recovery of Depressed Patients in Gaza Governorates. http://hdl.handle.net/20.500.12358/20903.

Eurofound. (2018). Burnout in the Workplace: A Review of Data and Policy Responses in the EU, Publication Office of the European Union. Luxembourg.

Fauth, E. B., Gerstorf, D., Ram, N., \& Malmberg, B. (2012). Changes in depressive symptoms in the context of disablement processes: Role of demographic characteristics, cognitive function, health, and social support. The Journals of Gerontology. Series B, Psychological Sciences and Social Sciences 67, 167-177. 
Frone, M. R. (2000). Work-family conflict and employee psychiatric disorders: The National Comorbidity Survey. Journal of Applied Psychology 85(6), 888-895. doi:10.1037/0021-9010.85.6.888

Gouveia, O. M. R., Matos, A. D., \& Schouten, M. J. (2016). Social networks and quality of life of elderly persons: a review and critical analysis of literature. Revista Brasileira de Geriatria e Gerontologia, 19(6), 1030-1040.

Gray, C., \& Rydon-Grange, M. (2020). Individual characteristics, secondary trauma, and burnout in police sexual and violent offending teams. The Police Journal, 93(2), 146-161.

Grzywacz, J. G., Arcury, T. A., Marín, A., Carrillo, L., Burke, B., Coates, M. L., \& Quandt, S. A. (2007). Work-family conflict: Experiences and health implications among immigrant Latinos. Journal of Applied Psychology, 92(4), 1119-1130. doi:10.1037/00219010.92.4.1119

Griffin, J. D., \& Sun, I. Y. (2018). Do work-family conflict and resiliency mediate police stress and burnout: a study of state police officers. American Journal of Criminal Justice, 43(2), 354-370.

Halif, M. M., Hassan, N., Saini, M. T., \& Athirah, N. (2020). Social Support as Predictor Towards Occupational Stress Among Employees in Major Telecommunication Companies in Malaysia. Malaysian Journal of Consumer and Family Economics, 24(1), 229-246.

Hilliard, B. J. (1981). Natural support systems and coping with major life changes. American Journal of Community Psychology, 7, 263-277.

Husain, W. (2014). The levels of depression, anxiety and stress in police officers. Acad Res Int, 5(4), 458-465.

Husain, W., \& Faize, F. A. (2018). Depression, Anxiety and Stress of Police Officers in Sensitive and Insensitive Police Stations. Archives of Psychiatry and Behavioral Sciences, 1(2), 2631.

Jacobsson, A., Backteman-Erlandson, S., Padyab, M., Egan Sjölander, A., \& Brulin, C. (2017). Burnout and association with psychosocial work environment among Swedish firefighters. Global Journal of Health Science, 9(5), 214-225.

Jones, C., \& Logan, J. (2013). Special Issue: Rediscovering Family and Kinship: new directions for social work theory, policy, and practice. Child and Family Social Work, 18(1), 1-4.

Jones, A. P., \& Butler, M. C. (1980). A role transition approach to the stresses of organizationally induced family role disruption. Journal of Marriage and the Family, 42(2), 367-376.

Katz, M. H., \& Piotrkowski, C. S. (1983). Correlates of Family Role Strain among Employed Black Women. Family Relations, 32(3), 367-376. doi:10.2307/584610

King, L. A., Mattimore, L. K., King, D. W., \& Adams, G. A. (1995). Family support inventory for workers: A new measure of perceived social support from family members. Journal of Organizational Behavior, 16(3), 235-258.

LaRocco, J. M., House, J. S., \& French, J. R. P. (1980). Social support, occupational stress, and health, Journal of Health and Social Behavior, 21, 202-218.

Lawson, K. J., Rodwell, J. J., \& Noblet, A. J. (2012). Mental health of a police force: estimating the prevalence of work-related depression in Australia without a direct national measure. Psychol Rep, (110), 743-752. doi: 10.2466/01.02.13.17.PR0.110.3.743-752.

Lincoln, K. D., \& Chae, D. H. (2011). Emotional support, negative interaction and major depressive disorder among African Americans and Caribbean Blacks: findings from the National Survey of American Life. Social Psychiatry and Psychiatric Epidemiology, 47(3), 361-372. doi:10.1007/s00127-011-0347-y 
Loriol, M. (2016). Collective forms of coping and the social construction of work stress among industrial workers and police officers in France. Theory \& Psychology, 26(1), 112-129. doi:10.1177/0959354315616877.

Mazerolle, S. M., Bruening, J. E., \& Casa, D. J. (2008). Work-Family Conflict, Part I: Antecedents of Work-Family Conflict in National Collegiate Athletic Association Division I-A Certified Athletic Trainers. Journal of Athletic Training, 43(5), 505-512. doi:10.4085/1062-605043.5.505

Mazlan, N. A., Ahmad, S. Z., Arifin, Z., Norwahi, N. A., \& Saad, M. F. M. (2021). The Influences of Work-Related Stress in Determining Work Performance Among Language Lecturers in Public Universities. International Journal of Academic Research in Business and Social Sciences, 11(8), 1161-1168.

Parasuraman, S., Greenhaus, J. H., Rabinowitz, S., Bedeian, A. G., \& Mossholder, K. W. (1989). Work and family variables as mediators of the relationship between wives' employment and husbands' well-being. Academy of Management Journal, 32(1), 185-201.

Purba, A., \& Demou, E. (2019). The relationship between organisational stressors and mental wellbeing within police officers: a systematic review. BMC Public Health, 19(1), 1286.

Queirós, C., Passos, F., Bártolo, A., Marques, A. J., da Silva, C. F., \& Pereira, A. (2020). Burnout and stress measurement in police officers: literature review and a study with the operational police stress questionnaire. Front. Psychol., 11, 587. https://doi.org/10.3389/fpsyg.2020.00587

Staines, G. L., \& Pleck, J. H. (1983). The Impact of Work Schedules on the Family. University of Michigan Press.

Stice, E., Ragan, J., \& Randall, P. (2004). Prospective Relations between Social Support and Depression: Differential Direction of Effects for Parent and Peer Support? Journal of Abnormal Psychology, 113(1), 155-159. https://doi.org/10.1037/0021-843X.113.1.155

Sheeber, L., Hops, H., Alpert, A., Davis, B., \& Andrews, J. (1997). Family support and conflict: Prospective relations to adolescent depression. Journal of Abnormal Child Psychology 25(4), 333-344.

Stogner, J., Miller, B. L., \& McLean, K. (2020). Police Stress, Mental Health, and Resiliency during the COVID-19 Pandemic, Am J Crim Just 45, 718-730. https://doi.org/10.1007/s12103-020-09548-y

Spector, P. E., \& Jex, S. M. (1998). Development of four self-report measures of job stressors and strain: Interpersonal Conflict at Work Scale, Organizational Constraints Scale, Quantitative Workload Inventory, and Physical Symptoms Inventory. Journal of Occupational Health Psychology, 3(4), 356-367. https://doi.org/10.1037/10768998.3.4.356

Thomas, L. T., \& Ganster, D. C. (1995). Impact of family-supportive work variables on workfamily conflict and strain: A control perspective. Journal of Applied Psychology, 80(1), 6-15. doi:10.1037/0021-9010.80.1.6

Tonsing, K., Zimet, G. D., \& Tse, S. (2012). Assessing social support among South Asians: The multidimensional scale of perceived social support. Asian Journal of Psychiatry, 5(2), 164-168. https://doi.org/10.1016/j.ajp.2012.02.012

Voydanoff, P. (1988). Work Role Characteristics, Family Structure Demands, and Work/Family Conflict. Journal of Marriage and the Family, 50(3), 749. doi:10.2307/352644

Wang, Y., \& Peng, J. (2017). Work-Family Conflict and Depression in Chinese Professional Women: The Mediating Roles of Job Satisfaction and Life Satisfaction. Int J Ment Health Addiction 15, 394-406. https://doi.org/10.1007/s11469-017-9736-0. 
Wang, Z., Inslicht, S. S., Metzler, T. J., Henn-Haase, C., McCaslin, S. E., Tong, H., \& Marmar, C. R. (2010). A prospective study of predictors of depression symptoms in police. Psychiatry Research, 175(3), 211-216.

Wickramasinghe, N. D., Wijesinghe, P. R., Dharmaratne, S. D., \& Agampodi, S. B. (2016). The prevalence and associated factors of depression in policing: a cross-sectional study in Sri Lanka. SpringerPlus, 5(1), 1776. https://doi.org/10.1186/s40064-016-3474-9

Wolter, C., Maria, S. A., Wörfel, F., Gusy, B., Lesener, T., Kleiber, D., \& Renneberg, B. (2018). Job demands, job resources, and well-being in police officers - a resource-oriented approach. Journal of Police and Criminal Psychology, 34(1), 45-5. 